\title{
Método de Planejamento Espacial - considerações sobre a investigação do território e do usuário no Design de Interiores
}

\author{
Environment Planning Method - territory and user investigation \\ considerations in Interior Design
}

\author{
OLIVEIRA, Gilberto Rangel de \\ Universidade Federal do Rio de Janeiro, D. Sc. \\ gilbertorangel@eba.ufrj.br \\ COSTA, Luiz Paulo \\ Universidade Federal do Rio de Janeiro, graduando \\ luizpaulocosta13@yahoo.com.br \\ PINNA, Julia \\ Universidade Federal do Rio de Janeiro, graduanda \\ pinnajulia@gmail.com
}

\section{RESUMO}

Este artigo descreve o Método de Planejamento Espacial e as técnicas de investigação do território e do usuário nas etapas iniciais do planejamento de projeto de design de interiores. A partir da análise do território e do usuário é possível realizar diagnoses, como possíveis ações projetuais, a fim de elaborar um entendimento global da relação do usuário com o espaço nos campos pragmáticos, funcionais, ergonômicos, simbólicos e culturais, dentre outros. Esta fase projetual é estudada e aplicada na disciplina de Composição de Interiores I, do curso Composição de Interiores (Design de Interiores), Escola de Belas Artes - UFRJ. O resultado desse mapeamento teórico produz um conceito de projeto, que deverá servir como fio condutor na elaboração de todo o projeto gráfico de design de interiores. Ao final do texto serão traçadas considerações sobre a utilização do método.

metodologia projetual; território; usuário; análise; diagnose; conceito

\begin{abstract}
This article describes the Spatial Planning Method and the territory and user investigation techniques in the design interior planning stage. From the analysis of the territory and the user it is possible to make diagnoses, as possible design actions, in order to elaborate a global understanding of the user relationship with the space in the pragmatic, functional, ergonomic, symbolic and cultural fields, among others. This design phase is studied and applied in the Interior Composition I course of the Interior Design course, School of Fine Arts - UFRJ. The result of this theoretical mapping yields a design concept, which should serve as the guiding thread of any interior design graphic design. At the end of the text considerations will be drawn about the use of the method.
\end{abstract}

design methodology, territory, user, analysis, diagnosis, concept. 


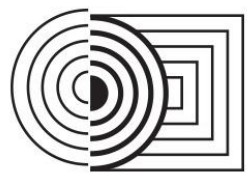

$17^{\circ}$ ERGODESIGN \& USIHC 2019

PUC-Rio, 11 a 13 de dezembro

Rio de Janeiro, RJ, Brasil $17^{\circ}$ Ergodesign - Congresso Internacional de Ergonomia e Usabilidade de Interfaces Humano Tecnológica: Produto, Informações Ambientes Construídos e Transporte

$17^{\circ}$ USIHC - Congresso Internacional de Ergonomia e Usabilidade de Interfaces Humano Computador

\section{INTRODUÇÃO - A ATIVIDADE DESIGN DE INTERIORES}

Brooker e Stone (2014, p. 12) explicam que o design de interiores (ou projeto de interiores) é uma atividade multidisciplinar que envolve a criação de ambientes internos que articulam 0 clima e a identidade por meio da manipulação dos volumes espaciais, da colocação de elementos específicos e mobiliário, além do tratamento das superfícies. "Em geral, descreve projetos que requerem poucas mudanças estruturais - ou nenhuma - na construção já existente, embora haja muitas exceções". O espaço é mantido em seu estado estrutural original e o novo interior é nele inserido. Aspectos como funcionalidade, segurança, saúde, ergonomia, conforto ambiental, sustentabilidade e estética, além de questões simbólicas e semânticas são considerados. Observa-se com ênfase a usabilidade dos ambientes, seja ele residencial, corporativo ou institucional. Moraes (2005, p.11) lembra que a "usabilidade não se relaciona apenas como o Ergodesign de Interfaces Computadorizadas, mas igualmente ao Ergodesign de Produtos, Informacional e de Ambiente Construído e Habitado."

Diante de tantos aspectos equânimes em grau de importância, é providencial utilizar-se de uma metodologia projetual que auxilie o aluno no desenvolvimento do seu trabalho. No percurso da disciplina obrigatória de Composição de Interiores I, trata-se de um projeto residencial de até $100 \mathrm{~m}^{2}$ com território e usuário definidos. Aplica-se um método analítico de análises de dados e diagnoses divididos por seções específicas. As análises e diagnoses são cruzadas, gerando diversos constructos nos campos pragmáticos, simbólicos e culturais. O resultado do processo leva o aluno, de forma individualiza, a concepção de um conceito de projeto. Este conceito, deverá ser o fio condutor da realização de todo planejamento espacial do projeto de interiores, traduzidos mais tarde através de representação gráfica por meio do projeto de apresentação. Face o acima exposto, será apresentado a aplicação do método utilizado e os resultados obtidos.

\section{METODOLOGIA DE PLANEJAMENTO ESPACIAL}

Roozenburg \& Eekels (1995), no seu livro Product Design: Fundamentals and Methods (Design de Produto Fundamentos e Métodos) apresentam uma explicação clara e direta sobre 0 assunto: "Metodologia de projeto é a ciência dos métodos que são ou que podem ser aplicados no projeto". Os autores evidenciam os dois significados que podem ser abordados no estudo sobre metodologia, na língua inglesa (assim como na língua portuguesa) da palavra "metodologia".

O primeiro significado é: a ciência ou o estudo do método, ou seja, a descrição, explicação e avaliação de métodos. O segundo significado de "metodologia" é: um corpo de métodos, procedimentos, conceitos e regras de trabalho empregadas por uma ciência particular, arte ou disciplina. Nos círculos acadêmicos, o termo "metodologia" normalmente tem o primeiro significado, ou seja, um campo de estudo e pesquisa (ROOZENBURG \& EEKELS, 1995, p. 29).

Coelho (2011) lembra que em alguns casos o uso da palavra metodologia no meio acadêmico costuma ter diferentes denominações, com ênfase ao "campo teórico de determinada área ou concentrando-se em grandes áreas, como é o caso de disciplinas que trabalham conteúdos a partir das ciências biológicas, sociais, humanas ou físicas". Os estudos realizados nessas 


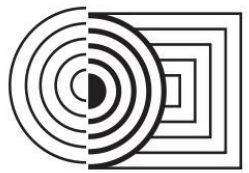

\section{$17^{\circ}$ ERGODESIGN \& USIHC 2019 \\ PUC-Rio, 11 a 13 de dezembro \\ Rio de Janeiro, RJ, Brasil}

$17^{\circ}$ Ergodesign - Congresso Internacional de Ergonomia e Usabilidade de Interfaces Humano Tecnológica: Produto, Informações Ambientes Construídos e Transporte

$17^{\circ}$ USIHC - Congresso Internacional de Ergonomia e Usabilidade de Interfaces Humano Computador

pesquisas costumam contemplar tanto a teoria metodológica em si, quanto sua aplicação em objetos específicos (metodologia aplicada). Neste caso, o estudo de disciplinas com esse entendimento privilegia a chamada metodologia científica "embora trabalhem, por vezes, com procedimentos metodológicos particulares a um campo delimitado". Nesse sentido, corroborase com o entendimento do autor sobre metodologia aplicada no campo do design, o qual tem sido empregado na atividade de design de interiores.

É o caso, por exemplo, do curso de Design, em que o chamado método projetual é ensinado. Justifica-se esse tipo de tratamento da disciplina sobre métodos no ensino do design em FUNÇÃO de peculiaridades da profissão, que exige conhecimentos sólidos de PROJETO (COELHO, 2011, p. 252 e 253).

No sentido de reforçar a importância do uso de métodos de projeto no desenvolvimento de espaços planejados, defendidos nesta pesquisa, traz-se a constatação de Karlen (2010, p. 16), onde o autor afirma que do ponto de vista prático e profissional o designer precisa de um processo eficiente e confiável ao qual deve recorrer sempre que se deparar com um projeto de design de interiores. "Reunir alguns fatos básicos e ficar olhando para uma planta baixa em branco até que a inspiração surja é uma abordagem totalmente inviável".

Considerando-se as assertivas acima expostas e com o objetivo de compreender a fundo a relação do usuário e o ambiente construído, aplica-se a metodologia de planejamento espacial. Esta metodologia trata de investigar os problemas de projeto durante a etapa do processo de planejamento do ambiente que se inicia assim que os problemas são apresentados ao aluno e termina quando o planejamento físico começa. Esta etapa pertence a fase inicial do projeto, que conforme consenso entre os autores de metodologia projetual no design, compreende: planejamento, análise, síntese e criatividade ${ }^{1}$.

O termo metodologia de planejamento espacial tem inspiração no método "Metodologia de Planejamento", (Karlen, 2010 p. 4-38), que de forma clara e concisa, "dedica mais atenção às partes preliminares do processo, ou seja, àquelas associadas ao planejamento e ao projeto." Karlen, que pertence ao Programa de Mestrado em Belas Artes - Arquitetura de Interiores do Moore College of Art \& Design, Filadélfia - EUA, trata a etapa do processo de planejamento do ambiente nas fases preliminares, que se iniciam assim que "os problemas de projeto são apresentados ao projetista (com ou sem um programa de necessidades) e que termina quando o planejamento físico começa - geralmente, com organogramas ou plantas baixas esquemáticas". O autor propõe os seguintes passos ou fases: (1) O processo de síntese; (2) $O$ programa de necessidades; (3) A matriz de critérios; (4) Esboços de planta baixa; (5) 0 preenchimento da matriz de critérios; (6) Os diagramas de relações.

A "Metodologia de Planejamento" de Karlen, encerra-se quando se inicia o planejamento físico e o desenvolvimento de plantas baixas, com todas as implicações espaciais e projetuais diversas - e a fase do planejamento de espaços e plantas baixas esquemáticas. É natural que o programa de necessidades sofra algumas adequações por conta de novos conceitos, relações e necessidades não identificadas na primeira fase.

1 OLIVEIRA, Gilberto Rangel. MÉTODOS DE PROJETO DE INTERIORES NO BRASIL. Revista ErgodesignHCI,

[S.I.], v. 6, n. Especial, p. 29 - 43, july 2018. ISSN 2317-8876. Disponível em: <http://periodicos.puc-

rio.br/index.php/revistaergodesign-hci/article/view/526>. Acesso em: 15 sep. 2019. 


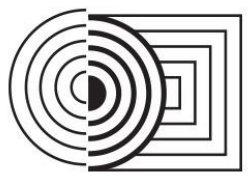

\section{$17^{\circ}$ ERGODESIGN \& USIHC 2019 \\ PUC-Rio, 11 a 13 de dezembro \\ Rio de Janeiro, RJ, Brasil}

$17^{\circ}$ Ergodesign - Congresso Internacional de Ergonomia e Usabilidade de Interfaces Humano Tecnológica: Produto, Informações Ambientes Construídos e Transporte

$17^{\circ}$ USIHC - Congresso Internacional de Ergonomia e Usabilidade de Interfaces Humano Computador

A metodologia de planejamento espacial apresentada aqui, é composta de uma estrutura de elementos formada por dados, análises e diagnoses - onde o foco está centrado no território e no usuário. Esta prática metodológica vem sendo aplicada, com algumas variações, como prática educativa projetual implantada no curso de Composição de Interiores (EBA-UFRJ), por professores das disciplinas de projeto já algum tempo ${ }^{2}$. Diante do fato que há muito pouco escrito sobre os métodos de planejamento espacial, principalmente do ponto de vista acadêmico, pretende-se aqui apresentar a aplicação do método, reexaminar seu conteúdo e apontar críticas construtivas sobre o uso da técnica.

\section{O TERRITÓRIO}

Moraes (2005, p. 78), aponta alguns esclarecimentos sobre qual território ${ }^{3}$ tratamos. Inicialmente a autora cita Santos (1993) que explica território "é mais que um conjunto de objetos mediante os quais trabalhamos circulamos, moramos, mas também um dado simbólico". Mais a adiante a autora lembra as ideias de Siergfried Lenz, que nos diz que "território é o lugar onde temos as nossas raízes, onde possuímos nossa casa, falamos nossa linguagem, pulsamos nossos sentimentos mesmo quando ficamos em silêncio. É o lugar onde sempre somos reconhecidos".

Por fim, a autora chama a atenção para Fischer (1989) que estabelece uma distinção entre território e espaço pessoal: "espaço pessoal é uma zona móvel e invisível que circunda as pessoas; território é visível e estável.”

Seguindo a mesma linha de raciocínio vale destacar o sentido amplo da palavra lugar. Risério (2019, p. 26), aponta para as considerações do teórico norueguês Christian Norberg-Schulz, no livro Uma nova agenda para a arquitetura, através do texto $O$ fenômeno do lugar, onde o autor escolhe a palavra lugar como uma expressão concreta para falar do ambiente (natural ou construído).

Lugar é algo mais do que uma localização abstrata. É "uma totalidade constituída de coisas concretas que possuem substância material, forma, textura e cor". E é uma realidade que deve ser pensada em termos ecológicos e antropológicos, desde que mesmo os lugares destinados a abrigar as funções mais básicas da existência, como comer e dormir, variam segundo climas e culturas. É assim que nosso filósofo parte para analisar a "estrutura do lugar", que pode ser uma cidade, um bairro, uma rua, uma casa. (RISÉRIO, 2019 apud NESBITT, 2010).

\subsection{A ergonomia do ambiente construído x usabilidade}

\footnotetext{
${ }^{2}$ As Profas. Nora Geoffroy e Ecilia Cirne, do curso de Composição de Interiores da Escola de Belas Artes - UFRJ, foram as idealizadoras da técnica de geração de dados, analises e diagnoses - sobre o território e o usuário, elaborando seu conteúdo, aplicando e desenvolvendo a técnica junto aos alunos das disciplinas de composição de interiores, testando e a aprimorando sua prática ao longo dos anos.

${ }^{3}$ Nota dos autores: Neste trabalho o termo território, afasta-se do natural entendimento que simplesmente refere-se a uma área delimitada sob a posse de um animal, de uma pessoa (ou grupo de pessoas), de uma organização ou de uma instituição. E afasta-se mais ainda, quando o termo é empregado na política (referente ao Estado Nação, por exemplo), na biologia (área de vivência de uma espécie animal) e na psicologia (ações de animais ou indivíduos para a defesa de um espaço, por exemplo).
} 


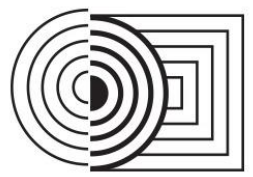

\section{$17^{\circ}$ ERGODESIGN \& USIHC 2019 \\ PUC-Rio, 11 a 13 de dezembro \\ Rio de Janeiro, RJ, Brasil}

$17^{\circ}$ Ergodesign - Congresso Internacional de Ergonomia e Usabilidade

de Interfaces Humano Tecnológica: Produto, Informações Ambientes

Construídos e Transporte

$17^{\circ}$ USIHC - Congresso Internacional de Ergonomia e Usabilidade

de Interfaces Humano Computador

Apesar de seu recente fortalecimento - vide o número de publicações em sessões e congressos específicos da área, vale destacar que conforme Moraes (2005 p. 68 apud Fraser, 1983 apud Buti, 1998) a Ergonomia trata do "estudo das características anatômicas, fisiológicas e psicológicas dos indivíduos no ambiente de trabalho, com a finalidade de gerar segurança, saúde, conforto e eficácia aos seus níveis otimizados." A Ergonomia ocupa-se não só da relação do homem com o objeto, mas também da relação do homem com o ambiente onde está inserido. Conforme explica Moraes (2005. p. 68, apud Buti, 1998) "a Ergonomia do Ambiente Construído deve ocupar-se de quem usará, que coisa será usada, mas principalmente onde virá a ser usada. O onde é o ambiente de destinação que deve ser analisado como lugar físico e sócio cultural que condiciona a interação entre o homem e o objeto."

Considerando-se os enunciados acima, destaca-se neste estudo a importância das análises dos aspectos de usabilidade entre o usuário e o território (ambiente) na metodologia de planejamento espacial. Neste conciso texto, o termo usabilidade é compreendido mais além que apenas sobre o nível de facilidade de uso de um produto. Faz-se aqui uso da definição da ISSO - International Standarts Association, que define usabilidade como "a efetividade, eficiência e satisfação com os quais usuários específicos atingem metas específicas em ambientes particulares" (ISSO 9241-11, 2018).

Para elucidar a aplicação do termo nas análises que são realizadas durante o uso da Metodologia de Planejamento Espacial, utiliza-se o mesmo entendimento de Moraes (2005, p. 11 e 12) que explica sobre os três aspectos: (1) efetividade - que se refere à extensão em que uma meta ou tarefa é alcançada. Para a ergonomia do ambiente construído "têm-se a capacidade de se movimentar de um ponto ao outro e desempenhar suas tarefas", como por exemplo os pontos de movimentação de uma dona de casa em sua cozinha, desempenhando determinada tarefa entre os pontos clássicos de funcionalidade: preparo/lavagem, cocção e armazenamento; (2) eficiência - se refere à quantidade de esforço que o indivíduo investe para atingir a sua meta. No que se refere a eficiência "no âmbito da ergonomia do ambiente construído, além do ir de um ponto ao outro do espaço, considera-se a economia de tempo e a segurança." Ainda no mesmo exemplo, melhorar as distâncias através da otimização do layout, para que a dona de casa percorra menos espaços entre os pontos de funcionalidade da cozinha, desprendendo menos esforços e otimizando o tempo; por fim, (3) satisfação - se refere ao nível de conforto e de aceitabilidade dos usuários ao usar produtos. Trata-se de um aspecto mais subjetivo, pois depende da avaliação e experiência pessoal do usuário. $\mathrm{Na}$ ergonomia do ambiente construído, "pode-se ter a satisfação com a paisagem, com a tranquilidade do ambiente, com a estética do ambiente construído, etc." No nosso exemplo da dona de casa e sua cozinha, não alcançaríamos níveis elevados de usabilidade se por acaso, 0 ambiente não considerasse também, aspectos relativos ao conforto ambiental, valorização da estética, entre outros.

As análises e diagnoses realizadas na metodologia de planejamento espacial, no âmbito da ergonomia do ambiente construído, visa observar a usabilidade como importante aspecto a ser considerado, que deve facilitar as atividades dos usuários, seja nas suas rotinas cotidianas, no trabalho ou lazer. Aspectos específicos de análise ergonômica no ambiente construído devem 


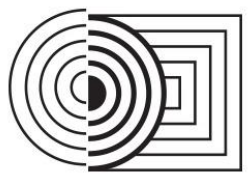

\section{$17^{\circ}$ ERGODESIGN \& USIHC 2019 \\ PUC-Rio, 11 a 13 de dezembro \\ Rio de Janeiro, RJ, Brasil}

$17^{\circ}$ Ergodesign - Congresso Internacional de Ergonomia e Usabilidade de Interfaces Humano Tecnológica: Produto, Informações Ambientes Construídos e Transporte

$17^{\circ}$ USIHC - Congresso Internacional de Ergonomia e Usabilidade

de Interfaces Humano Computador

ser observados quando analisamos o usuário e o ambiente, conforme artigo já publicado anteriormente. $^{4}$

\section{O USUÁRIO}

Todo mundo é usuário, se considerarmos a relação do homem com o território e sua interação. Moraes (2011, p. 92-93) explica que o usuário não é um monólito. "Aquele que denominamos usuário é determinado por nossas perspectivas. Existe o usuário como uma abstração. Existe 0 usuário como sujeito de testes. Existe o usuário como um ideal que se deve considerar, e cujos limites e capacidades devemos incorporar ao projeto".

$\mathrm{Na}$ disciplina de Composição de Interiores I, por razões pedagógicas, faz-se uso de um usuário ficcional. O professor da matéria desenvolve uma história fictícia onde propõe uma persona com características particulares de vida pessoal e profissional, valores, hábitos, rotinas e suas principais atividades. Estes dados são analisados em separado e mais tarde faz-se os cruzamentos necessários com os dados obtidos a partir da análise do território estudado considerando os aspectos pragmáticos, funcionais, ergonômicos, culturais e simbólicos. Nesse sentido, investiga-se sobre o usuário proposto: idade, sexo, origem - história pessoal; profissão/ocupação; características pessoais, temperamento, valores; rotina, hábitos - o cotidiano: sono, alimentação e trabalho; lazer: hobbies, colecionismo, entretenimento; relações pessoais - família, amigos; usuários da moradia - funcionários e prestadores de serviço; equipamento mobiliário, acessórios e objetos de arte existentes; demandas; qualificação da ambiência.

Os dados de território e usuário são organizados em planilha onde registra-se as informações levantadas que geram análises sobre a relação do aspecto espacial e o usuário. Estas análises possibilitam ao aluno realizar reflexão avaliativa, confronto de informações e cruzamento de diferentes dados, somados ao repertório pessoal do profissional. Em seguida, a partir das análises realizadas, geram-se diagnoses, que podem determinar ações que irão balizar as possíveis soluções projetuais.

\section{A METODOLOGIA DE PLANEJAMENTO ESPACIAL E O CONCEITO}

\subsection{Aplicação da Metodologia de Planejamento Espacial}

A metodologia de planejamento espacial na disciplina Composição de Interior I, inicia-se com a investigação do território existente considerando a interação do usuário com a cidade, o bairro, o entorno imediato, a rua, o edifício e a unidade residencial. A partir da técnica de observação (in loco) e análise de documentos específicos, levanta-se dados sobre: localização geográfica; características físicas e climáticas; aspectos históricos; patrimônio cultural (bens de natureza material e imaterial, paisagem cultural); aspectos físicos, econômicos, socioculturais; sistema

\footnotetext{
${ }^{4}$ OLIVEIRA, Gilberto Rangel; MONT'ALVÃO, Claudia Renata. O PROCESSO DE PROJETO DE INTERIORES E O USO DA ERGONOMIA NA PRÁTICA SEGUNDO A VISÃO DE PROFISSIONAIS E USUÁRIOS. Revista

ErgodesignHCI, [S.I.], v. 5, n. Especial, p. 61 - 72, dec. 1969. ISSN 2317-8876. Disponível em:

<http://periodicos.puc-rio.br/index.php/revistaergodesign-hci/article/view/351>. Acesso em: 15 sep. 2019.
} 


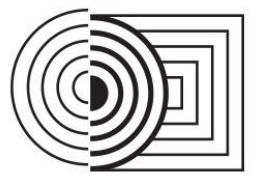

\section{$17^{\circ}$ ERGODESIGN \& USIHC 2019 \\ PUC-Rio, 11 a 13 de dezembro \\ Rio de Janeiro, RJ, Brasil}

$17^{\circ}$ Ergodesign - Congresso Internacional de Ergonomia e Usabilidade de Interfaces Humano Tecnológica: Produto, Informações Ambientes Construídos e Transporte

$17^{\circ}$ USIHC - Congresso Internacional de Ergonomia e Usabilidade

de Interfaces Humano Computador

viário, tráfego e meios de transporte; fluxos de pedestres; uso e ocupação do solo institucional, comercial, residencial, misto; cobertura vegetal; microclima; passeios; ruídos; cobertura vegetal e iluminação pública. No edifício verifica-se aspectos tais como: acessibilidade, áreas comuns, formas de coleta de resíduos, número de pavimentos e unidades habitacionais circulações verticais e horizontais, orientação solar, materiais utilizados, envasaduras, entre outros. Por fim, na unidade habitacional, a partir da planta arquitetônica, faz-se uma análise minuciosa, sobre área construída, funções dos compartimentos, dimensões, pé-direito, vãos de ventilação e iluminação, paisagem, vãos de acesso (tipologia, material, dimensão); invasão de privacidade interna e externa - olfativa, auditiva e visual.

Os dados devem ser enriquecidos com informações levantadas a partir de leis, decretos, normas, publicações oficiais e dados obtidos de fontes fidedignas, como sites institucionais (público e/ou privado), publicações, periódicos e associação de moradores de bairro, por exemplo. Diante dos dados levantados, inicia-se as análises que são realizadas considerandose os dados observados in loco, e sua relação com os documentos pesquisados. Através do cruzamento dos diversos dados mapeados em uma planilha, realiza-se as mais diversas análises considerando-se aspectos pragmáticos, funcionais, simbólicos e culturais.

A etapa seguinte é elaboração de diagnoses, que são as ações projetuais que podem ser realizadas visando o melhor entendimento entre as necessidades do usuário e sua relação com o espaço. Organiza-se o processo por seções. Assim há diagnoses propostas no planejamento da relação usuário e a cidade, usuário e o bairro, usuário e a rua; usuário o edifício e usuário e a unidade habitacional.

Todos os dados, análise e diagnose da metodologia de planejamento espacial são organizados em um formulário, tipo planilha, onde o aluno pode visualizar por seções as relações entre 0 usuário e o ambiente de forma organizada e clara.

\subsection{0 conceito}

Os resultados das análises dos dados levantados e as diagnoses realizadas, na metodologia de planejamento espacial produzem um número elevado de informações que o aluno deve aprimorar e reorganizar através de resumos estendidos. É fundamental a análise atenta do aluno para destacar os aspectos que irão de fato contribuir com soluções projetuais adequadas e descartar informações que podem não ser necessárias para esta fase de planejamento espacial.

Objetiva-se nesta fase do trabalho formular um conceito que traduza a concepção formal do projeto. Nesse sentido, entende-se conceito como uma "representação mental de um objeto abstrato ou concreto que se mostra como instrumento fundamental do pensamento em sua tarefa de identificar, descrever e classificar os diferentes elementos e aspectos da realidade." (HOUAISS, 2009).

Coelho (2011, p. 168) explica que "conceito se estabelece a partir da compreensão e extensão de um objeto, englobando seus atributos, qualidades e elementos constitutivos." Nesse sentido, entende-se que a correta compreensão e elaboração das análises e diagnoses, realizados na metodologia de planejamento espacial sobre determinados dados, poderão contribuir 


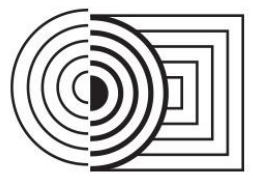

\section{$17^{\circ}$ ERGODESIGN \& USIHC 2019 \\ PUC-Rio, 11 a 13 de dezembro \\ Rio de Janeiro, RJ, Brasil}

$17^{\circ}$ Ergodesign - Congresso Internacional de Ergonomia e Usabilidade de Interfaces Humano Tecnológica: Produto, Informações Ambientes Construídos e Transporte

$17^{\circ}$ USIHC - Congresso Internacional de Ergonomia e Usabilidade

de Interfaces Humano Computador

significativamente com o enriquecimento do conceito proposto pelo aluno. Gibbs (2014, p. 62) apresenta uma visão mais mercadológica e pragmática no processo de elaboração do conceito.

A autora explica que "alguns profissionais baseiam o processo criativo em um fato concreto e trabalham principalmente com a análise do projeto." Desta forma a autora cita o exemplo que o designer pode solicitar ao cliente três palavras que transmitam as características desejadas, como leveza, elegância e conforto. Gibbs (2014) alerta ainda que "outros profissionais podem buscar inspiração nos elementos naturais próprios do local onde o imóvel se localiza".

Por fim, Gibbs (2014) chama atenção para "ao estabelecer o conceito de projeto, o designer deve levar em consideração as limitações de fatores como o orçamento, o próprio imóvel e o estilo de vida do cliente." Tais considerações demonstram a visão pragmática e comercial da autora, que apesar de significativos, no entender dos autores deste artigo, corre-se o risco de resvalar em conceitos repetitivos e que talvez, traduzam menos a identidade do usuário na concepção formal do projeto.

\section{CONSIDERAÇÕES FINAIS}

A metodologia de planejamento espacial, visa compreender as relações entre o território e usuário. Trata-se de uma ferramenta metodológica que, devido seu formato proposto, é construída entre todos os alunos que participam da disciplina e o professor, considerando o território e o usuário específicos, utilizados como estudo de caso a cada semestre letivo. Face a exposição realizada, traça-se algumas considerações:

- O aspecto quantitativo e qualitativo dos dados levantados, depende do empenho dos alunos e da orientação efetiva do professor da disciplina;

- As análises e diagnoses precisam ser exaustivamente estimuladas junto aos discentes, considerando que a pouca experiência em análises de dados e reflexões, constituem-se como um problema de formação acadêmica endêmico;

- A dinâmica de aplicação e elaboração da planilha do método de planejamento espacial, realizado de forma colaborativa em grupo, favorece a participação dos discentes que se sentem estimulados a contribuir para a construção do trabalho e troca de ideias;

- Considerando o número de itens o trabalho muita das vezes torna-se exaustivo;

- A qualidade dos dados e as análises adequadas irão gerar diagnoses úteis para etapas seguintes do projeto;

- A deficiência no levantamento dos dados, bem como análises mal estruturadas, irá gerar diagnoses deficientes, o que pode comprometer as etapas seguintes do projeto;

- A experiência do docente na aplicação do método de planejamento espacial, é um atributo a ser considerado de forma positiva;

- Os conceitos elaborados a partir da planilha elaborada no método de planejamento espacial, tem demonstrado importante subsídio como ferramenta para criação de conceitos criativos, que favorecem as etapas seguintes do projeto.

A ação projetual é uma atividade complexa. O projeto requer uma atuação criativa, acúmulo de informação, conhecimento e alguma experiência. Enfrenta desafios complicados, como definir 
com precisão os reais problemas dos usuários e planejar possíveis soluções, considerando níveis de necessidades a serem atendidos. Ribeiro e Mont'Alvão (2005, p. 87) são taxativas em afirmar que "é importante observar e registrar como o usuário do ambiente o percebe e o experiência". Explicam que isto significa "compreender em que medida o desempenho do ambiente construído influencia o comportamento do usuário, mas também como este se molda aquele desempenho, modificando ou não esse ambiente, no decorrer de seu uso, dando origem assim a um novo padrão de ambiente construído". A metodologia de análise espacial, possibilita uma investigação crítica e rica de aspectos do campo funcional e simbólico da interação entre usuário e ambiente. Os conceitos e ideias concebidos irão traduzir um projeto único e específico para cada usuário.

\section{REFERÊNCIAS BIBLIOGRAFICAS}

BROOKER, G. \& STONE, S. O que é design de interiores. Tradução: André Botelho. São Paulo: Senac, 2014. Título Original: What is interior design?

COELHO, L. A. (org.). Conceitos-chave em design. Rio de Janeiro: 2AB / Novas ideais, 2011.

GIBBS, Jenny. Design de interiores: guia útil para estudantes e profissionais. Tradução Claudia Ardión. Barcelona: Gustavo Gili, 2014. Título original: Interior Design

HOUAISS, A. Dicionário Houaiss da língua portuguesa. Rio de Janeiro: Objetiva, 2009

ISO 9241-11:2018 Ergonomics of human-system interaction -- Part 11: Usability: Definitions and concepts. Disponível em: https://www.iso.org/obp/ui/\#iso:std:iso:9241:-11:ed-2:v1:en. Acesso em: 15. sept. 2019

KARLEN, Mark. Planejamento de espaços internos. Tradução: Alexandre Salvaterra. 3ed. Porto Alegre: Bookman, 2010. Título original: Space Planning Basics

MORAES, A. de (org.) Ergodesign do ambiente construído e habitado. Rio de Janeiro: $2 A B$, $4^{\text {a }}$ ed. 2005.

MORAES, A. de. Usuário. In: COELHO, Luiz Antônio (org.). Conceitos-chave em design. Rio de Janeiro: 2AB/Novas ideias, 2011. p. 92-93.

RIBEIRO, Lúcia e MONT'ALVÃO, Claudia. Ergonomia do Ambiente Construído: teoria e prática. In: MORAES, Anamaria (org.). Ergodesign do ambiente construído e habitado. Rio de Janeiro: $2 A B, 4^{a}$ ed. 2005

RISÉRIO, Antonio. A casa no Brasil. Rio de Janeiro: Topbooks, 2019, p. 26

ROOZENBURG, N. F. M. e EEKELS, J. Product Design: Fundamentals and methods. West Sussex, UK: John Wiley \& Sons, 1995. 